\title{
Analysis of Road Traffic Accident Costs in Sudan Using the Human Capital Method
}

\author{
Adam I. A. Mofadal*, Kunnawee Kanitpong \\ Transportation Engineering Program, Asian Institute of Technology (AIT), Klong Luang, Bathumthani, Thailand \\ Email: "adammofadal@gmail.com, "amofadal@hotmail.com
}

Received 6 February 2016; accepted 27 March 2016; published 30 March 2016

Copyright $@ 2016$ by authors and Scientific Research Publishing Inc.

This work is licensed under the Creative Commons Attribution International License (CC BY). http://creativecommons.org/licenses/by/4.0/

(c) (i) Open Access

\begin{abstract}
In this study, we used the Human Capital (HC) accident analysis method, to determine the road traffic accident costs in Sudan in two successive years (2010 and 2011) with slight modifications to the recommended and known framework in the way it handles currently and future accident cost components. We evaluated and compared the significance and impact of the economic loss caused by road traffic accidents in Sudan using detailed information on road traffic accident casualties, classified by severity level, vehicle type, and other key parameters such as discount rates and medical and insurance information for Sudan in its entirety. The total cost of road traffic accidents in Sudan in 2010 was estimated at US \$391 million, which represents 0.57\% of the Gross Domestic Product (GDP), while in 2011 the cost was calculated to reach US \$413 million, representing $0.62 \%$ of GDP. Findings show that the amount of accident costs is estimated to a certain extent at less than $1 \%$ of the total GDP of the country in the two estimation years, but we believe that the evaluation process used fulfilled the eligibility criteria of HC studies and that the produced values for Sudan are valid and reliable. Unit costs for each crash severity level were also estimated in the two years such as death, disability, serious injury, slight injury, and vehicle damage. Death or fatality was equal to US $\$ 38,932$ and 39,508 ; disability was equal to US $\$ 43,113$ and US $\$ 45,165$; serious injury was equal to US $\$ 6963$ and US \$7596; slight injury was equal to US $\$ 2570$ and US $\$ 3198$ and vehicle damage only was equal to US $\$ 2268$ and US \$2579 in the assessment years 2010 and 2011, respectively.
\end{abstract}

\section{Keywords}

Road Traffic Accident, Accident Costs, Human Capital, Loss in Quality of Life, Sudan, Accident Severity Level

"Corresponding author. 


\section{Introduction}

Worldwide deaths as a result of traffic accidents have reached epidemic proportions. Current indications show that annually global fatalities on the roads exceed 1.24 million people while 20 - 50 million suffer injuries. Fatalities due to traffic accidents in low- and middle-income countries are contributing, to over $90 \%$ of total global fatalities, although those countries had only 53\% of the total registered vehicles in the world (WHO, 2013) [1]. For more than a decade in Sudan, the government and community as a whole have faced enormous economic and social loss due to human and property damage arising from the adverse effects of road accidents. This can easily be observed by looking at the rising patterns of fatality risk, fatality rates, and motorization levels in Sudan as shown in Figure 1.

Identifying and determining the extent and dimensions of these costs, together with their components in terms of socioeconomic aspects, will provide a platform for better understanding of the impacts of disaster losses on taxpayers' federal income. Moreover, the estimated accident costs can be used to measure the benefits of selecting certain road safety interventions to prevent or eliminate the severity of traffic accidents.

Accident statistics from traffic police reports in 2010 and 2011 clearly show the existing trend for economical losses due to traffic accidents in Sudan as illustrated in Figure 1. However, there are no government officials, road safety stakeholders, or anyone in the community as a whole who have a clear picture of the size and dimension of losses which might need proper and reliable socioeconomic assessment. Studies of accident cost analysis in most developed countries and some developing countries have usually been conducted with the objectives of maximizing national output (GDP) and social welfare (individual lifestyle levels). Two methods used to determine accident costs are the Human Capital method (HC) and the Willingness-to-Pay method (WTP) (Silcock, 2003) [4].

HC and WTP accident cost analysis methods are quite different in concept, specifically when estimating the value of life, and the two methods produce different figures. HC can measure human output or productivity while WTP seeks to assess the trade-off between wealth and risk. In other words, HC deals with lifetime consumption and can efficiently achieve maximum national income objectives (BTE, 2000) [5]. In certain literature, the HC method has been widely used in developed and developing countries as a useful tool for analyzing accident costs. In recent years, many studies have been carried out using mainly the HC method (Connelly and Supangan, 2006; Thongchim et al., 2007; Antić et al., 2011) [6]-[8]. However, this method has two significant limitations including its incapacity to deal with intangible or indirect accident costs, and the consequences of ex-

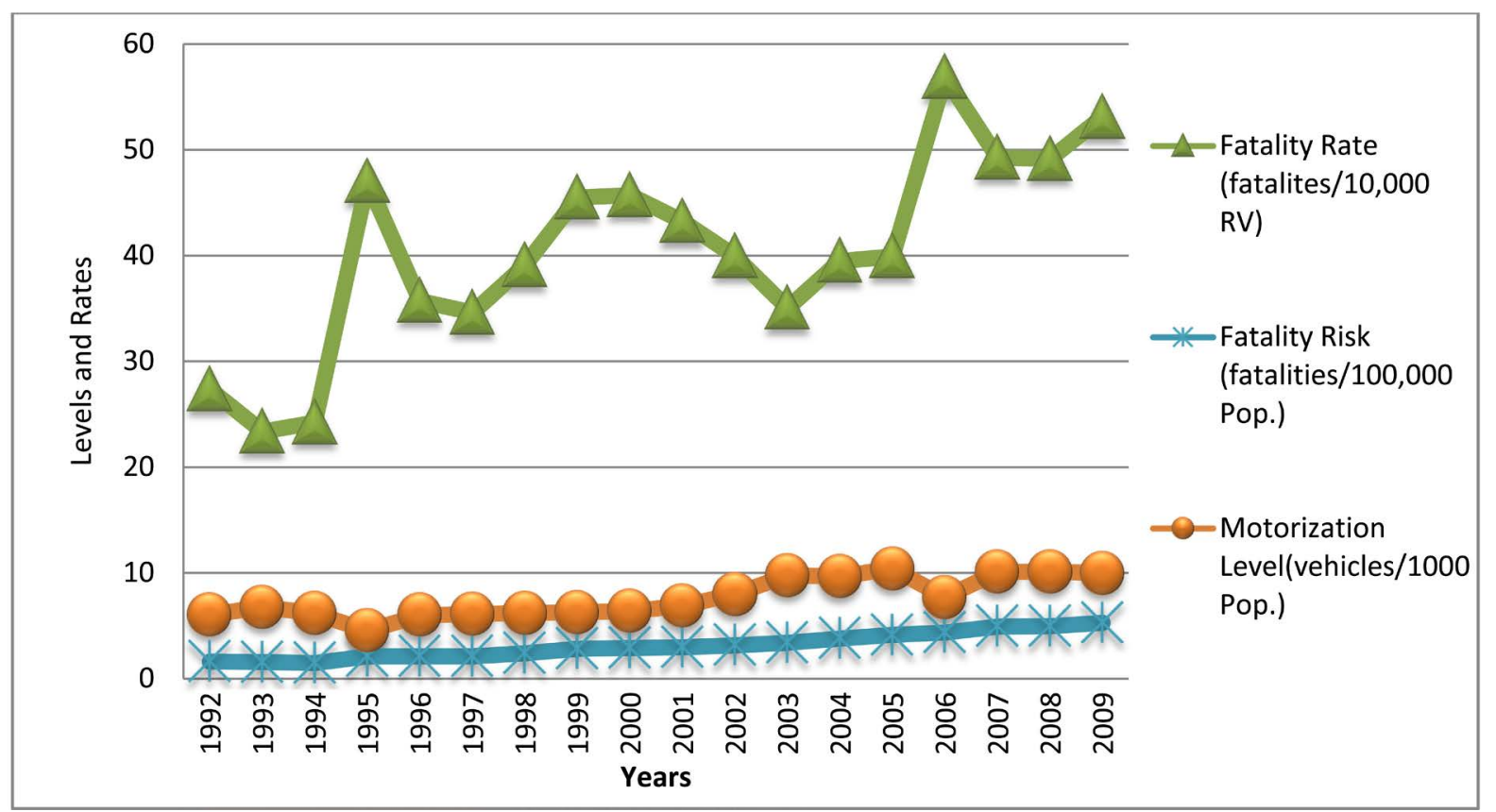

Source: (CBS, 2011; GDT, 2010) [2] [3]

Figure 1. Fatality rates, risk, and motorization level trends from 1992 to 2009. 
tending life (partial equilibrium) issues. However, the HC method has some useful advantages: 1) the data required for analysis are reliable and readily available; 2) it can produce consistent and transparent results, and 3) it is simple to use (BTE, 2000) [5]. Silcock (2003) [4] recommends the HC method as a useful application tool for analyzing accident costs in developing countries as a starting point. Based on the recommendations and advantages of the HC mentioned earlier, it was applied to determine accident costs in this study.

The objectives of this study are as follows:

- To analyze road accident costs in Sudan by using the HC method for the data collected in the years 2010 and 2011.

- To determine the unit cost for each crash severity level.

Additionally, this study can contribute positively towards decision making for Sudan country planners and road safety stakeholders as well as to the knowledge of mankind by identifying the extent of road traffic accident costs in Sudan with respect to human productivity and loss or damage to property in relation to the gross domestic product (GDP).

\section{Materials and Methods}

\subsection{Accident Cost Approach and Framework}

The estimated cost of road accidents using the Human Capital (HC) method has been used in many different ways. To achieve the most, reliable accident costs estimate, the analysis process needs to satisfy the required eligibility criteria. The criteria include the followings; 1) the analysis data should not be too old, 2) the underreporting problem in traffic accident data must be overcome, 3) the total estimation should include the cost of damage to property only, and 4) the direct and indirect accident costs, and the cost estimate relate to the loss in quality of life (Elvik, 2000) [9]. It should be noted that this study has fulfilled the eligibility criteria as a starting point for conducting accident cost analysis in Sudan.

In this study, the HC method is applied to analyze accident costs in Sudan according to the analysis framework recommended by Silcock (2003) [4] and cost categories and components used by Connelly and Supangan (2006) [6]. The appropriate analysis framework for each country is based on the size and weight of each cost category and component and the type of available accident data existing in that country. Thus, the framework proposed for HC accident cost analysis in Sudan is modified based on Silcock (2003) [4] as presented in Figure 2.

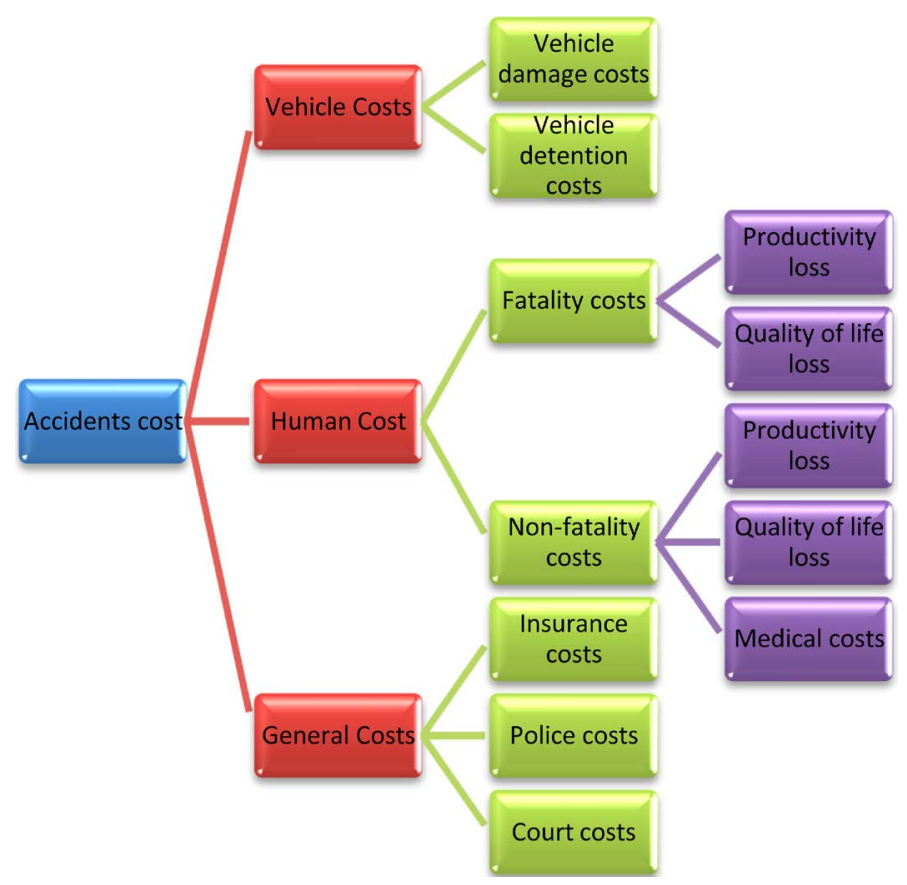

Figure 2. HC accident cost analysis framework for Sudan (after Silcock, 2003) [4]. 
The main differences between the framework in this study and the findings by Silcock (2003) are the expansion of administration and PDO cost categories and the way in which existing cost components and accommodation of other cost components can be handled in the future. The administration and PDO cost categories are renamed as general costs and vehicle costs respectively, as shown in Figure 2. Possible future cost components may be the costs of travel delay or non-vehicle PDO costs if the required data exists. The HC gross-loss-ofoutput approach was used in this study because it is simple and widely used in road accident cost studies (Al-Masaeid et al., 1999; Anh et al., 2005; Thongchim et al., 2007) [7] [10] [11].

The loss of productivity due to fatality was generated according to the following equation used in most HC studies

$$
\text { Lost output (fatality) }=\sum_{i=1}^{N} W(1+g) i /(1+r) i \quad[11]
$$

where: $W=$ average year per capita GDP;

$G=$ annual growth rate;

$R=$ discount rate;

$I=$ average number of years of lost output per accident fatality.

The average fatality age was used similarly to other previous studies. This is to avoid the problem of undervalued of extremely young and old victims due to the Labour-market regulations and laws, identifying the starting production and retirement ages in each country (Anh et al., 2005; Luathep \& Tanaboriboon, 2005; Antic et al., 2011) [8] [11] [12]. Meanwhile, other cost components were estimated by multiplying the unit cost for each category by the total number of each accident severity level. The detailed estimation formulas are presented in Table 1.

\subsection{Data Collection}

Based on the proposed cost framework, secondary data on road accidents were collected from the General Directorate of Traffic, Ministry of Interior and National Medical Commission, Federal Ministry of Health, and the State Ministry of Health in Khartoum, Sudan. The data for estimating the loss of business earnings was obtained mainly from different federal government agencies such as the Central Bank of Sudan, the Central Bureau of Statistics (CBS), the Federal Ministry of Finance and National Economy, and the Federal Ministry of Human Resource and Labor. This data includes the discount rate (interest rate), GDP growth rate, and GDP per capita for the years 2010 and 2011. The data for estimating the cost of human loss (subjective costs of grief, pain, and suffering to accident victims), vehicle damage costs, and insurance administration costs was obtained from the Insurance Supervisory Authority-Federal Ministry of Finance. However, estimates of vehicle detention costs, policing costs, traffic court costs, and medical expenses in private hospitals were all obtained through direct interviews with the relevant authorized personnel in the specific organizations.

A face-to-face survey was conducted to collect data for loss in household yield (community and family), and this data was collected through personal and household questionnaires in two cities representative of the entire Sudan region: Khartoum, the capital of Sudan, and Nyala the capital city of South Darfur State. The main question is: what amount of time does a person spend with his family and community after completing his regular working hours in social activities ${ }^{1}$ on a daily basis? [10]. The survey covers 1400 respondents with 1000 respondents coming from Khartoum and 400 respondents from Nyala. A pilot study was conducted in Khartoum to test the question if the respondents can understand clearly. After that, by the pre-test results, the questionnaire was modified prior to the final survey in two cities. The overall response rate for the survey was $99.85 \%$. The descriptive statistical analysis technique was used to analyze data for household yield.

The World Health Organization (WHO) has provided recommendations regarding the importance of applying a 30-day definition of road traffic accident death for all countries. The aim of this recommendation is to develop the integration of crash data monitoring and provide cross-country comparisons (WHO, 2013) [1]. In Sudan, traffic police commonly report accident fatalities with the definition of death occurring within 24 hours only, and therefore WHO adjusted the fatality data from 2010 by adding $30 \%$ to the existing data reported by police.

\footnotetext{
${ }^{1}$ The "social activities" represent activities performed by respondents and usually spent with their family and community after the regular 8 hours of daily work. These include: child care, teaching children, shopping, social visits, and participating in community events (meetings, parties, etc.)
} 
Table 1. Sudan road traffic accident costings by the HC theory of the estimation process.

Cost Component

oss of Productivity

(A1)

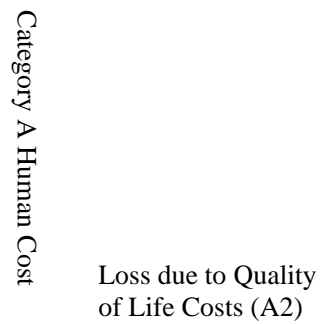

Medical Costs (A3)

Vehicle Damage and

Detention

Costs (B)

$\frac{0}{4}$ W

Policing Costs (C1)

ח8

Court Costs (C2)

Insurance Costs

(C3)
Estimation Formula

1) Lost productivity in terms of income loss due to fatalities

$=\left[\right.$ No. fatalities $\times$ average age in years] $\times$ [foregoing income per year using $\left.\sum_{i=1}^{N} W(1+g) i /(1+r) i\right]$

2) Lost productivity in terms of income loss due to disabilities

(during treatment or recovery period by injury type)

$=[$ No. of fracture injuries $] \times[$ No. of days in hospital $] \times[$ average wage per day $]+[$ No. of injuries $] \times$

[No. of days in hospital] $\times$ [average wage per day]

$=[$ No. of injuries $] \times[$ No. of days in hospital $] \times$ [average wage per day $]$

3) Lost productivity in terms of income loss from serious and slight injuries

(during treatment or recovery period)

$=[$ No. of serious injuries $] \times[$ No. of days in hospital $] \times$ [average wage per day $]+[$ No. of slight injuries $]$

$\times$ [No. of days in hospital] $\times$ [average wage per day]

4) Lost output in terms of income loss due to time lost normally spent by casualties with their families and community in social activities

$=[$ No. of fatalities $] \times[$ No. of hours per lost years $] \times$ [average wage per hour $]+[$ No. of disabilities $] \times$ [No. of hours per lost months] $\times$ [average wage per hour] + [No. of injuries] $\times$ [No. of hours per lost days] $\times$ [average wage per hour]

Total quality of life costs

$=[$ No. of fatalities $] \times[$ amount compensated by insurance companies $]+[$ No. of injuries $] \times[$ amount compensated by insurance companies]

1) Total medical costs (disabilities) $=$ [No. of disability cases with facture injuries] $\times$ [average hospitalization days] × [average hospitalization expenses per/person/day]

2) Total medical costs (serious injuries) $=[$ No. of serious injury cases] $\times$ [average hospitalization days] $\times$ [average hospitalization expenses per/person/day]

3) Total medical costs (slight injuries) $=$ [No. of slight injury cases] $\times$ [average hospitalization days] $\times$ [average hospitalization expenses per/person/day]

4) Total cost of emergency services $=$ [No. of total injury cases] $\times$ [average emergency cost per/person]

1) Total vehicle damage costs

$=[$ No. of total vehicles damaged] $\times$ [average vehicle damage costs]

2) Total vehicle detention costs

$=[$ No. of total repaired vehicles (by vehicle type) $] \times$ [average vehicle repair period (in days) $] \times$ [average vehicle rental cost/day]

Total police administration costs $=[$ No. of road traffic accident cases reported by police] $\times$ [average police administration costs per case]

Total court administration costs $=$ [No. of road traffic accident trial cases finalized by court $] \times$ [average judicial system administrative costs per case]

Total insurance administration costs

$=[$ No. of road traffic accident fatalities] $\times$ [average insurance compensation per fatality] $\times$ [insurance administrative cost per case (percentage according to the company's performance)] + [No. of road traffic accident injuries] $\times$ [average insurance compensation per injury] $\times$ [insurance administrative cost per case (percentage according to the company's performance)] + [No. of road traffic accident PDO vehicles] $\times$ [average insurance compensation per PDO vehicle] $\times$ [insurance administrative cost per case (percentage according to the company's performance)]

\section{Results and Discussion}

\subsection{Unit Cost Data}

According to the proposed cost analysis framework, the data on road traffic accidents obtained from the General Directorate of Traffic, Ministry of Interior, Sudan is classified by severity level and casualty group together with the mean age of fatalities for the years 2010 and 2011 as shown in Table 2.

\subsubsection{Human Cost}

The data for the estimation of loss of business earnings was obtained from independent sources. This data includes the discount rate (interest rate) from the Central Bank of Sudan (Table 3) and GDP growth rate from the Central Bureau of Statistics (Table 4). The GDP per capita amounts are US \$1658 and US \$1562 for 2010 and 
Table 2. Road traffic accident casualties and PDO vehicle numbers in 2010 and 2011.

\begin{tabular}{|c|c|c|c|c|c|c|c|}
\hline Year & $\begin{array}{c}\text { Property Damage } \\
\text { (Vehicle) Only (PDO) }\end{array}$ & $\begin{array}{l}\text { Slight Injuries } \\
\text { (SLI) }\end{array}$ & $\begin{array}{l}\text { Serious Injuries } \\
\text { (SEI) }\end{array}$ & Disability & $\begin{array}{l}\text { Total } \\
\text { Injuries }\end{array}$ & Fatalities & $\begin{array}{c}\text { Mean Age of } \\
\text { Fatalities (Years) }\end{array}$ \\
\hline 2010 & 45,330 & 14,810 & 7261 & 1430 & 23,501 & 2758 & 35 \\
\hline $\begin{array}{c}\text { No. of } \\
\text { Casualties/Accidents }\end{array}$ & 1.1125 & 1.2315 & 1.4325 & 1.4325 & - & 1.3279 & \\
\hline 2011 & 43,748 & 14,209 & 6469 & 1525 & 22,203 & 2667 & 33 \\
\hline $\begin{array}{c}\text { No. of } \\
\text { Casualties/Accidents }\end{array}$ & 1.111 & 1.3778 & 1.3682 & 1.3682 & - & 1.2903 & \\
\hline
\end{tabular}

Source: 1) The General Directorate of Traffic, Ministry of the Interior, Sudan; 2) The National Medical Commission, Federal Ministry of Health, Sudan.

Table 3. Interest (discount) rate values in Sudan.

\begin{tabular}{ccccc}
\hline Year & 2009 & 2010 & 2011 & Average Interest Rate (Discount Rate) \\
Percentage Interest Rate & 9 & 9 & 12 & 10 \\
\hline
\end{tabular}

Source: Central Bank of Sudan.

Table 4. GDP growth rate in Sudan.

\begin{tabular}{cccccccccccc}
\hline Year & 2002 & 2003 & 2004 & 2005 & 2006 & 2007 & 2008 & 2009 & 2010 & 2011 & Average \\
Percentage GDP Growth Rate & 7.5 & 6.6 & 4.4 & 5.2 & 7.7 & 5.8 & 3.9 & 4.5 & 6.5 & 2.5 & 5.46 \\
\hline
\end{tabular}

Source: Central Bureau of Statistics, Sudan.

Table 5. Times allocated for family or community in social activities.

\begin{tabular}{|c|c|c|c|}
\hline \multicolumn{2}{|c|}{ Study Area } & Sudan & \\
\hline \multirow{2}{*}{ Statistics } & $\mathrm{N}$ & 1398 & \\
\hline & Mean & 2.99 hour/day & 3 hours/day \\
\hline \multicolumn{2}{|c|}{ Standard Error of Mean } & & \\
\hline \multicolumn{2}{|c|}{ Standard. Deviation } & & \\
\hline
\end{tabular}

Source: Household Survey 2013.

2011, and the GDPs are US $\$ 68.31$ billion and US $\$ 66.11$ billion for 2010 and 2011, respectively (IMF, 2013) [13]. The retirement age in Sudan is 60 years, and the hourly production rate for ordinary labor standards is about US \$0.56/hour.

The loss in household yield (community and family) data was collected through a personal and household questionnaire survey with the descriptive statistical analysis results shown in Table 5.

The typical assessment of loss in quality of life cost component cannot be agreed upon because it represents pain, grief, and suffering sustained due to a road traffic accident (Elvik, 2000) [9]. In Sudan, estimating the value of the loss in quality of life usually accords with the settlement awarded by the traffic court and compensation paid by insurance companies for all casualty severity levels. Data for the loss in quality of life was gathered from three insurance companies. These three companies represent more than $80 \%$ of the business insurance sector in Sudan, and the average compensation values in 2010 for fatality and injury cases are US \$7828.4 and US \$1976.4, respectively. The average compensation values in 2011 for fatality and injury cases are US \$8321 and US \$2581, respectively.

The medical costs represent all casualties, including outpatient and inpatient treatment for serious and minor injury cases in terms of emergency treatment, physician and nursing services, X-rays, CTS, Ultra-sound, surgery, physical therapy, drugs, and bedding (Al-Masaeid et al., 1999) [10]. The costs for disability cases involve additional inpatient treatment, rehabilitation, or long-term care services (Connelly and Supangan, 2006) [6]. The data for estimating emergency outpatient and inpatient costs, together with the duration of severity level treatment was obtained as a result of personal interviews with certain national health organization managers, hospital staff, and some hospital cost studies. Thus, the treatment cost at public and private hospitals in Sudan obtained as mean values for each treatment is set to narrow the gap between public and private hospitals, and also to remove any signs of under-estimation of the medical cost component since public hospitals are always cheaper than pri- 
vate due to the subsidy policy of public hospitals (Mohan, 2002) [14]. Table 6 shows the injury treatment duration for each severity level while Table 7 shows the medical expenses per person for three treatment levels at six hospitals with their average values.

\subsubsection{Vehicle Costs}

Vehicle costs are commonly divided into two cost components: auto repair damage costs and vehicle detention (unavailability of vehicle) charges. The auto repair costs in 2010 and 2011 were obtained from the claims data of three insurance companies in Sudan. The average auto repair costs per case obtained from these three companies are US \$838 in 2010 and US \$1128 in 2011. The vehicle detention cost data in terms of rental rate or repair time was obtained from personal interviews with the transport companies, fleet owners, and private car owners. These companies were identified by the National Chamber of Land Transport in Sudan. The average values are as follows: rental cost per day for trucks and buses is US\$188.15 with 19 days for repair time, while the rental cost per day for vans and cars is US $\$ 43.15$ with 6 days for repair time (Al-Masaeid et al., 1999) [10].

\subsubsection{General Costs}

General accident costs were categorized into three cost components: traffic police, court, and insurance. The traffic police costs include accident drawings, towing of damaged vehicles, investigation and reports, time spent by traffic police personnel, vehicles and equipment for each crash. The average cost of one accident for traffic police is US $\$ 28.24$. The traffic court costs cover administration carried out in the judicial system by court personnel, estimated as employees' hourly working wage values. The traffic court costs were estimated at US $\$ 15.37$ per accident case finalized by the tribunal. Lastly, for insurance claim fees, this cost is calculated from compensation payments finalized by insurance company staff taken at $15 \%$ in Sudan by law. The average percentage of insurance costs obtained from three companies stands at $19.167 \%$ and $15.74 \%$ from the claims values, for 2010 and 2011 respectively.

The adjustment factor of $30 \%$ recommended by the WHO was applied to the total fatalities. For year 2010, and the number of fatalities was increased from 2758 to 3582, while for 2011, the number of fatalities rose from 2667 to 3464 . Other crash severity levels remained unchanged.

\subsection{Total Estimated Accident Costs}

The HC (gross output) approach explained in Section 2.1 was used to analyze the data collected, and the total accident costs in Sudan for the years 2010 and 2011 were estimated and categorized as follows: human cost, vehicle costs, and general costs as shown in Table 8.

Table 6. Injury treatment duration.

\begin{tabular}{llcc}
\hline & Casualty Class & Treatment Duration & Average Treatment Duration in Days \\
\hline \multirow{2}{*}{ Disability } & Complex Fracture & $4-6$ months & 60 \\
& Non-Complex Fracture & $1-3$ months & 14 \\
Inpatient & & $7-21$ days & 2 \\
\hline
\end{tabular}

Source: National Medical Commission, Federal Ministry of Health, Sudan.

Table 7. Medical cost data.

\begin{tabular}{ccccc}
\hline Hospital Name & Hospital Type & Emergency/Cost/Person (US \$) & Inpatient/Day Cost (US \$) & Outpatient/Day Cost (US \$) \\
\hline Ombadda & Public & 24.71 & 85.9 & 137.28 \\
N. Khartoum & Public & 24.71 & 96.6 & 82.57 \\
Umdawanban & Public & 24.71 & 87 & 43.98 \\
Jabel Awliya & Public & 24.71 & 571.8 & 50.14 \\
Royal Care & Private & 35 & 500 & 77.5 \\
Jarash & Private & 30 & 318.80
\end{tabular}

Source: Federal, State Ministries of Health, Royal Care and Jarash Private Hospitals, Sudan. 
The findings of the cost assessment procedure explained in Section 2.1 to identify the unit cost per crash severity level in Sudan are presented in Table 9.

Table 8. Estimated road traffic accident costs in Sudan for 2010 and 2011 given in US \$.

\begin{tabular}{|c|c|c|c|c|c|c|}
\hline \multirow{2}{*}{ Cost Category } & \multicolumn{2}{|c|}{ Estimated Cost US \$ } & \multicolumn{2}{|c|}{ Percentage of Cost Category } & \multicolumn{2}{|c|}{ Percentage of Total Costs } \\
\hline & 2010 & 2011 & 2010 & 2011 & 2010 & 2011 \\
\hline \multicolumn{7}{|l|}{ Human Cost } \\
\hline Loss of Productivity & $83,445,745$ & $81,544,310$ & 34.43 & 31.92 & 23.23 & 21.40 \\
\hline Loss in Quality of Life & $68,038,104$ & $79,498,050$ & 28.03 & 31.12 & 18.94 & 20.80 \\
\hline Medical Costs & $91,031,656$ & $94,425,324$ & 37.54 & 36.96 & 25.33 & 24.70 \\
\hline Subtotal & $242,515,505$ & $255,467,684$ & 100.0 & 100.0 & 67.50 & 66.90 \\
\hline \multicolumn{7}{|l|}{ Vehicle Costs } \\
\hline Vehicle Damage Costs & $37,986,940$ & $49,347,744$ & 40.52 & 47.73 & 10.58 & 12.98 \\
\hline Vehicle Detention Costs & $55,750,242$ & $54,035,212$ & 59.48 & 52.27 & 15.52 & 14.22 \\
\hline Subtotal & $93,736,782$ & $103,382,956$ & 100.0 & 100.0 & 26.10 & 27.10 \\
\hline \multicolumn{7}{|l|}{ General Costs } \\
\hline Policing Costs & $1,725,662$ & $1,626,568$ & 7.52 & 7.17 & 0.47 & 0.43 \\
\hline Court Costs & 907,214 & 789,757 & 3.95 & 3.50 & 0.25 & 0.22 \\
\hline Insurance Costs & $20,321,743$ & $20,700,114$ & 88.53 & 89.33 & 5.68 & 5.35 \\
\hline Subtotal & $22,954,619$ & $23,116,439$ & 100.0 & 100.0 & 6.40 & 6.00 \\
\hline Total Accident Costs & $359,206,906$ & $381,967,079$ & & & 100.0 & 100.0 \\
\hline
\end{tabular}

Table 9. Average unit cost for each crash severity level in Sudan given in US \$.

\begin{tabular}{|c|c|c|c|c|c|c|}
\hline \multirow{2}{*}{ Cost Components } & \multirow{2}{*}{ Year } & \multicolumn{5}{|c|}{ Severity Level } \\
\hline & & Fatality & Disability & Serious Injury & Slight Injury & PDO (Vehicle) \\
\hline \multirow{2}{*}{$\begin{array}{l}\text { Loss of Productivity } \\
\text { Unit Cost (US \$) }\end{array}$} & 2010 & 29,571 & 771.61 & 86.20 & 12.32 & - \\
\hline & 2011 & 29,845 & 798.50 & 86.20 & 12.32 & - \\
\hline \multirow{2}{*}{ Quality of Life Unit Costs (US \$) } & 2010 & 7828 & 1976 & 1976 & 1976 & - \\
\hline & 2011 & 8321 & 2581 & 2581 & 2581 & - \\
\hline \multirow{2}{*}{ Medical Unit Costs (US \$) } & 2010 & - & $39,956.64$ & 4492 & 168 & - \\
\hline & 2011 & - & $41,349.5$ & 4492 & 168 & - \\
\hline \multirow{2}{*}{$\begin{array}{l}\text { Vehicle Damage Unit } \\
\text { Costs (US \$) }\end{array}$} & 2010 & - & - & - & - & 838 \\
\hline & 2011 & - & - & - & - & 1128 \\
\hline \multirow{2}{*}{$\begin{array}{c}\text { Vehicle Detention Unit } \\
\text { Costs (US \$) }\end{array}$} & 2010 & - & - & - & - & 1230 \\
\hline & 2011 & - & - & - & - & 1235 \\
\hline \multirow{2}{*}{ Traffic Police Unit Costs (US \$) } & 2010 & 21.26 & 19.70 & 19.40 & 22.93 & 25.41 \\
\hline & 2011 & 21.30 & 20.58 & 20.60 & 20.33 & 25.20 \\
\hline \multirow{2}{*}{ Traffic Court Unit Costs (US \$) } & 2010 & 11.50 & 9.88 & 10.60 & 12.48 & 13.86 \\
\hline & 2011 & 11.50 & 9.87 & 11.20 & 11.06 & 13.50 \\
\hline \multirow{2}{*}{ Insurance Unit Costs (US \$) } & 2010 & 1500.5 & 378.8 & 378.8 & 378.8 & 160.62 \\
\hline & 2011 & 1310 & 406 & 406 & 406 & 178 \\
\hline \multirow{2}{*}{ Total Unit Costs (US \$) } & 2010 & 38,932 & 43,113 & 6963 & 2570 & 2268 \\
\hline & 2011 & 39,508 & 45,165 & 7596 & 3198 & 2579 \\
\hline
\end{tabular}




\subsection{Estimated Accident Costs after Underreporting Adjustment (for Fatalities Only)}

According to the WHO, the adjustment was applied to the unreported number of deaths. The total estimated road accident costs in Sudan were then adjusted as shown in Table 10.

The total estimated road traffic accident costs was compared with Sudan's GDP in the years 2010 and 2011, and the results show that the percentage of total road traffic accident costs relative to GDP is about $0.57 \%$ in 2010 and $0.62 \%$ in 2011 . The proportion of each cost category in the total estimated road traffic accident costs in Sudan is presented in Figure 3.

This study clearly explains that the total cost of road traffic accidents in Sudan for 2010 and 2011 is approximately US \$391 million and US $\$ 413$ million, respectively. As a matter of fact, the estimated cost appears to be quite small in comparison to GDP (less than 1\% of GDP). However, this value is possibly underestimated and can be explained. For example, the underestimation could be due to the shortcomings in accident statistics recorded by the police (underreporting), and the conservative nature of the HC method used in the analysis which produces humble estimates, especially with the loss in enjoyment of life (loss in quality of life) due to sudden

Table 10. Total accident costs in years 2010 and 2011 after underreporting adjustment.

\begin{tabular}{cccccccc}
\multirow{2}{*}{ Crash Severity Level } & Year & \multicolumn{3}{c}{ Number of Causalities } & Unit Cost/Severity Level & $\begin{array}{c}\text { Total Cost/Severity Level } \\
\text { (US \$) }\end{array}$ \\
\cline { 3 - 5 } Feported & Unreported & Total & 38,932 & $139,454,424$ \\
\multirow{2}{*}{ Fatality } & 2010 & 2758 & $824^{*}$ & 3582 & 39,508 & $136,855,712$ \\
& 2011 & 2667 & $797^{* *}$ & 3464 & & $60,185,748$ \\
Disability & 2010 & 1396 & - & 1396 & 43,113 & $68,786,295$ \\
Serious Injury & 2011 & 1523 & - & 1523 & 45,165 & $50,795,085$ \\
& 2010 & 7295 & - & 7295 & 6963 & $49,153,716$ \\
Slight Injury & 2011 & 6471 & - & 6471 & 7596 & $38,061,700$ \\
PDO (Vehicle) & 2010 & 14,810 & - & 14,810 & 2570 & $45,440,382$ \\
Total Accident Costs & 2011 & 14,209 & - & 14,209 & 3198 & $102,808,440$ \\
(US \$) & 2010 & 45,330 & - & 45,330 & 2268 & $112,826,092$ \\
\end{tabular}

Source: *World Health Organization (WHO) [1] global status report, 2013; ** Estimated according to WHO guidance.

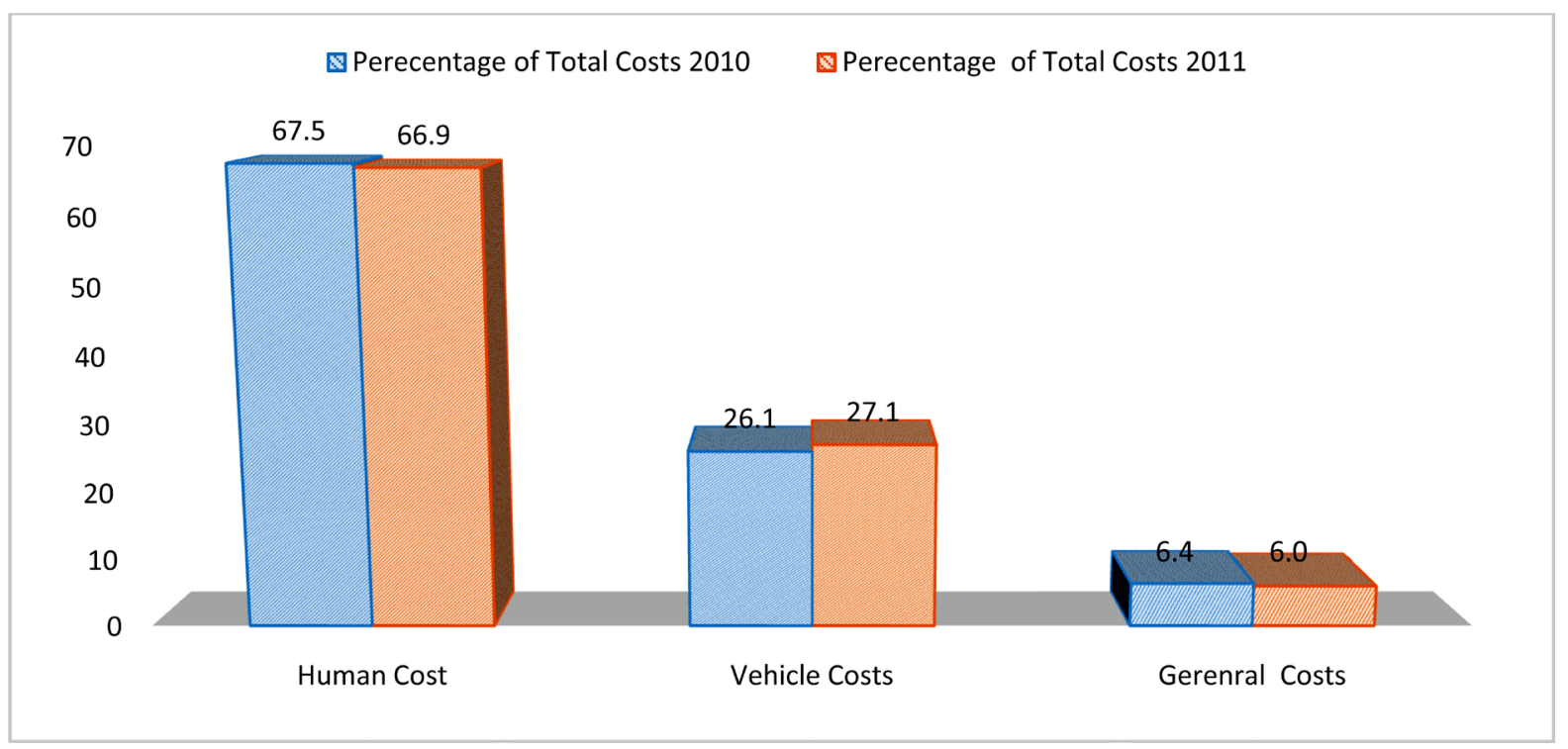

Figure 3. Percentage of each accident cost category from the total costs in 2010 and 2011. 
death, as also indicated by Connelly and Supangan (2006). Other reasons for the small amount of estimated accident costs are the exclusion of other cost components such as travel delays and non-vehicle PDO. Nevertheless, the results produced from the modified framework used in this study are still within the range of $0.5 \%$ to $5.7 \%$ reported by Elvik (2000) [9] and 0.3\% to 4\% reported by Jacobs and Astrop (1999) [15] of GNP or GDP. Therefore, these results can be considered as reasonable accident cost values for Sudan. In fact, the cost of road accident estimates achieved in this study are shown to be extraordinarily significant for a country already suffering from poor infrastructure, especially in the road and health sectors (AICD, 2011; CBS, 2011; Shariff, 2004) [2] [16] [17].

This study also clarifies cost estimates for all severity levels of road traffic casualties in Sudan. The reliability and the validity of such estimates depends mainly on the data used and reasonableness of the assumptions adopted in estimating certain items; therefore, it's hard to compare them to estimates from other countries for several reasons:

- The difference in valuation methods used in estimating the costs has impacted on cost levels (Elvik, 1995) [18].

- The difference in the methods of calculating the value of life enjoyment or the emotional well-being.

- The differences in countries' incomes and standards of per capita income (Trawén et al., 2002) [19].

- The traffic safety policies, the cultural and the social differences between different people (Al-Masaeid et al., 1999) [10].

However, this study can compare accident costs and unit costs for fatality and disability severity levels with other countries as presented in Table 11.

Table 11. Accident cost estimates and unit costs for fatality and disability severity levels by HCM in different countries.

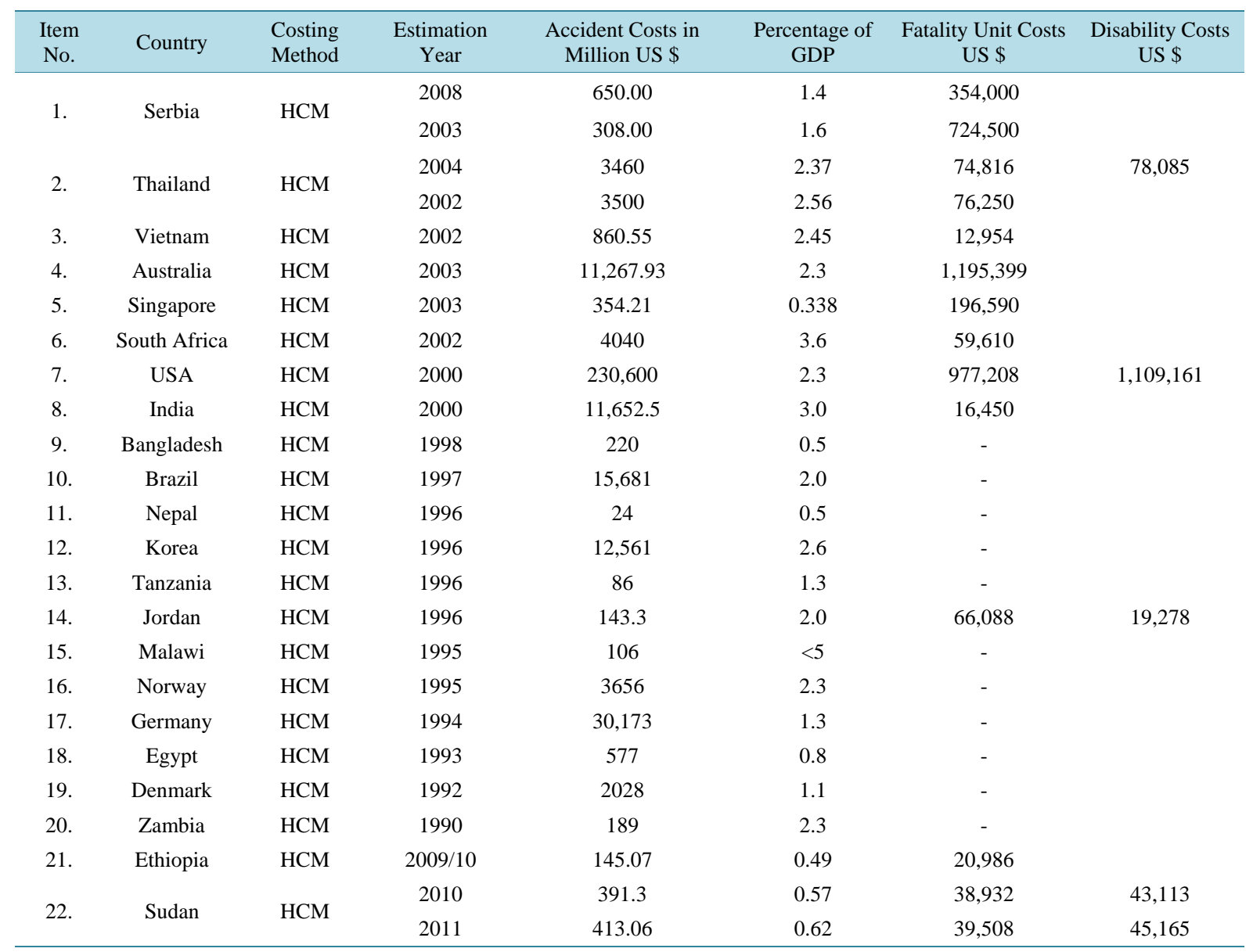

Source: Jacobs and Astrop, 2000; de Beer and van Niekerk, 2004; Chin, H. et al., 2006; Murad, 2011; Luathep \& Tanaboriboon, 2005 [12] [15] [20]-[22]. 
The findings from accident cost analysis research in most countries clearly supports the assumption that the income level of each country is a fundamental factor in determining the value of statistical life (VOSL) generated through HC or WTP valuation methods (McMahon and Dahdah, 2008) [23]. Comparing the ratio of VOSL (fatality cost) to GDP per capita calculated from road accident analysis results in Sudan using the HC method, indicated that the results are within the range of many developing countries identified and reported by McMahon and Dahdah (2008) [23] as shown in Table 12.

The percentage of each cost category from the total estimated accident costs in Sudan is presented in Figure 3. The figure mentioned shows that the category representing the percentage of vehicle costs amounts to $26.10 \%$ in 2010 and $27.1 \%$ in 2011, respectively. These findings are reasonable in comparison to the results of certain previous studies by L. Blincoe et al. (2002) [24] around 26\%, Connelly and Supangan (2006) [6] around 33.3\%, and Antić et al. (2011) [8] about 29\%. Meanwhile, the percentage of general costs as part of road traffic accidents amounted to $6.4 \%$ in 2010 and $6.0 \%$ in 2011. The produced general cost is reasonable compared with findings of previous researchers: Thongchim et al. (2007) [7] about 3\%, Connelly and Supangan (2006) about $6.67 \%$, and Al-Masaeid et al. (1999) about 8.3\%. The percentage of human loss of road traffic accidents in Sudan accounts for up to $67.50 \%$ and $66.90 \%$ relative to the total accident costs in 2010 and 2011, respectively. These values are high and clearly indicate huge human losses due to traffic accidents. Compared to the results of previous studies in (Antić et al., 2011) [8] human loss reached 71\%, while in a study conducted by Thongchim et al. (2007) [7] it reached 64\% and Connelly and Supangan (2006) [6] amounting to 55.97\%.

One considerable finding of this study is the percentage of medical treatment costs in Sudan. This accident cost component reached $25.33 \%$ in 2010 and $24.70 \%$ in 2011. The medical expenses are obviously substantial since they include all injuries and non-fatalities such as disabilities. This higher value is achieved due to the details and complete information available upon which the estimates are based, especially the details of injuries, disabilities, and type of complex fractures which usually require longer periods of treatment and recovery (up to six months in some cases). The research conducted by Blincoe et al. (2002) [24] found that a similar percentage of $25 \%$ was reached for the medical treatment of non-fatality victims of road traffic accidents. As a consequence, the estimated unit cost of disability is higher than that of fatality. The high estimated cost of disability is not surprising since other studies have reached the same conclusions (L. Blincoe et al., 2002) [24] and (Thongchim et al., 2007) [7] as shown in Table 11.

Some cost components in road traffic accidents are not included in this study due to lack of information. These are the loss due to the destruction of non-vehicles and cost of travel time delays for road users. Assessment of the quantitative impact of these components on the total cost of accidents from previous research would be useful. For instance in some previous studies, the cost payable towards the value of non-vehicles is insuffi-

Table 12. Comparison with the ratio of fatality cost (VOSL) to the per capita GDP of different developing countries with Sudan.

\begin{tabular}{cccccc}
\hline Country & VOSL in US \$ & GDP/Capita US \$ & VOSL/GDP per Capita & Year & Method \\
\hline Bangladesh & 71,066 & 1710 & 42 & 2004 & HC \\
Cambodia & 18,864 & 317 & 60 & 2002 & HC \\
Indonesia & 92,433 & 3125 & 30 & 2004 & HC \\
Lao & 4617 & 336 & 14 & 2003 & HC \\
Latvia & $1,042,743$ & 18,140 & 58 & 2004 & HC \\
Lithuania & $746,531.525$ & 12,027 & 62 & 2004 & HC \\
Myanmar & 51,245 & 1545 & 33 & 2004 & HC \\
Philippines & 41,330 & 982 & 42 & 2003 & HC \\
Poland & 573,806 & 14,984 & 38 & 2004 & HC \\
Thailand & 222,056 & 6958 & 32 & 2004 & HC \\
Vietnam & 53,063 & 2475 & 21 & 2004 & HC \\
Sudan & 38,932 & 1658 & 24 & 2010 & HC \\
\hline
\end{tabular}

Source: McMahon and Dahdah, 2008; IMF, 2013 [13] [23]. 
cient as it did not exceed $0.2 \%$ according to Connelly and Supergun (2006) and about 4.4\%, according to Thongchim et al. (2007) [7]. Meanwhile, the cost of travel delay loss in previous studies was shown to be useful to some extent as it reached 11\% in Balance et al. (2002), 9.65\% in Connelly and Supangan (2006) [6] and 13.9\% in Thonghim et al. (2007) [7]. Therefore, including these components as part of any future accident costing studies in Sudan would be useful if the required information is available.

Finally, the estimation values of accident costs in Sudan for the years 2010 and 2011 are limited to some extent, due to various reasons including the economic analysis used, underreporting problems, and the small compensation amounts for loss in quality of life. In addition, two further aspects of road traffic accidents are acknowledged by many researchers: these being mainly the long-range effect of traffic accidents and social differences in road accident hazards, which also have an impact on real accident costs (ETSC, 2007) [25]. Despite the limitations mentioned, the study of road accident costs in Sudan is undoubtedly sufficient and fulfills the eligibility criteria of the HC method.

\section{Conclusions and Recommendations}

The purpose of this study is to analyze the economic cost of road traffic accidents in Sudan, by using the Human Capital (HC) method for the years 2010 and 2011. The estimated total accident costs were then compared with Sudan's GDP in the same years. In addition, this study is also to provide an estimation of the unit cost for each crash severity level.

Sudan is going through a period of development, especially in the road transport sector, and that may put all road users at increasing risk of becoming victims of traffic accidents as in other developing African countries; therefore, the impact of road traffic accidents must be assessed and evaluated. As recommended by many researchers, the HC accident cost analysis method used in this research is quite satisfactory since it is easy to implement, and the necessary data requirements can be achieved.

This study suggests that road traffic accident costs the Republic of Sudan approximately US \$391.31 million in 2010 and about US \$413.06 million in 2011. These estimated costs of casualties and PDO are far less than the actual accident costs. The generated low estimation conditions are due to many reasons such as underreporting and accuracy of accident data, impact of long-term consequences of road traffic injuries, and the socioeconomic burden of road accident casualties (ETSC, 2007) [25]. Two other significant factors affecting the outcome of this study are the HC valuation method used in the estimation process and the real GDP per capita in Sudan used for estimating the loss in productivity of all accident fatalities (Masniak, n.d.) [26].

The cost of human loss is estimated to account for $67.50 \%$ of the total accident costs in 2010 and up to $66.90 \%$ in 2011, while vehicle damage costs are estimated to account for $26.10 \%$ and $27.10 \%$ in 2010 and 2011 , respectively. Additionally, general cost accounts for $6.4 \%$ in 2010 and $6.0 \%$ in 2011 of the total road traffic accident cost estimations in those years.

Scaling the amount of total accident costs with Sudan's GDP gives $0.57 \%$ in 2010 and $0.62 \%$ in 2011. This range is within the values reported by both Jacobs and Astrop (2000) [15] and Elvik (2000) [9]. The evaluation process applied in this study fulfills the eligibility criteria of HC studies, and, therefore, the results achieved can be considered valid and reliable for Sudan.

Estimated unit costs for each crash severity level are given as follows: death or fatality about US \$38,932 and 39,508 , disability about US $\$ 43,113$ and 45,165, serious injury about US \$6963 and 7596, slight injury about US \$2570 and 3198, and vehicle damage only about US \$2268 and 2579 in the assessment years of 2010 and 2011 , respectively. The ratios of fatality costs (VOSL) to GDP per capita calculated in the results of this study using the HC method are 24 and 25 in 2010 and 2011, respectively. It is indicated that Sudan study results are within the range of the developing countries identified and reported by McMahon and Dahdah (2008) [23].

Identifying the total cost of road traffic accidents reflects the actual dimensions of the problem in terms of both social and economic burdens. This huge socioeconomic loss caused by road traffic accidents dislocates the already meager financial resources and limited medical services of the whole country. Meanwhile, the plurality of the casualties affected by road traffic accidents is those within the most productive age range and just starting to repay their debt to society. Moreover, this study clearly points out the scale and magnitude of the problem. This rising toll of traffic accidents can destroy the overall efforts of the government as well as the whole society in maximizing the national output in Sudan.

However, the achieved results and findings of this study and evaluation process of the total road traffic acci- 
dents in Sudan using the HC accident costing valuation method highlight the following suggestions.

- Study findings necessitate that decision makers, as well as all those concerned with road safety, need to work very hard at increasing public awareness, particularly in setting out proper strategic action plans to promote road safety issues at all levels. Meanwhile, the allocation of sufficient financial resources and implementation of planned road safety interventions will help in mitigating the severity of this serious public health problem.

- The HC analysis approach used, and the results achieved in Sudan have highlighted many issues to be addressed in terms of research and policy recommendations. In other words, to ensure the accuracy of road traffic accident costs, matters such as incomplete road accident data, long-term burden of traffic accidents, and the socioeconomic impact of traffic accidents at all levels should be considered (ETSC, 2007) [25].

Results achieved through this study may be useful in measuring the benefits to the community from implementing the national road safety strategic plan launched in 2011. The long-term burden of road traffic accidents in Sudan is unknown due to lack of detailed data and research. Therefore, the following recommendations for both research and policy implications are essential to explain this aspect of accident impacts.

- Intensive and deep assessment as to the suitability of the currently applied quality-of-life (Diya) levels and compensation to those who sustain disability and serious injury or fatality as a result of road traffic accidents.

- The number of disabled people due to road accidents is increasing significantly in Sudan (16\% of the total seriously injured people in 2010 and 19\% in 2011). These situations necessitate the speeding up of implementation of already approved road safety programs aimed at reducing the number of fatalities and serious injuries.

In Sudan, social differences in road traffic accident risk are unknown. However, accident socioeconomic research in most countries indicates that those on low incomes or poor people are much more likely to be involved in road accidents than those on high incomes. This trend can be applied to all road user groups. The followings are recommendations regarding the socioeconomic aspects of road traffic accidents:

- A detailed study to explain the association between social status and road traffic accidents and the influence of certain factors such as age, income, and educational level should be conducted to cover all road users.

- A policy aimed to improve road users' behavior within low-income communities must be developed and applied.

- There are some accident cost components such as losses due to the destruction of non-vehicles and costs of travel delays for road users, which have not been included in this study due to lack of data. These two cost components should be part of any future accident costing studies in Sudan.

\section{Acknowledgements}

We would like to thank The Central Bureau of Statistics (CBS), Dr. Yasin and the General Directorate of Traffic, Sudan, together with Colonel Walid and Colonel Osama for providing us with most of the required data used in this research. We are also thankful to Mrs. Nawal Tayib Elasma from the Insurance Supervisory Authority, Sudan; Associate Professor Mahjoub from the National Medical Commission; Mr. Adam Salih from the State Ministry of Health, Khartoum, Sudan; Jarash International Specialized Hospital, Royal Care International Hospital, Mr. Khalid Kheiri-the Traffic Court Judge, and Mr. Bashari from El Leel Co. Ltd. We wish to thank Mr. Ahmed Ibrahim and Mr. Mohamed Elmustafa for their extraordinary efforts in facilitating the majority of the contacts with the government and private organizations. Special thanks go to Ms. Khalda Abdelghafar and Mr. Mohamed Gumaa for their valuable assistance with disability data entry work. We are grateful to Dr. Hassan and Dr. Taravudh for providing language and editing help in the early stages of this paperwork.

\section{References}

[1] WHO (2013) Global Status Report on Road Safety 2013: Supporting a Decade of Action. World Health Organization, Geneva.

[2] CBS (2011) Statistical Series 2011: Central Bureau of Statistics. CBS, Khartoum.

[3] GDT (2010) Annual Traffic Accidents and Violations Report in Khartoum. General Directorate of Traffic in Sudan, Sudan.

[4] Ross Silcock—Babtie Group Ltd., TRL (2003) Guidelines for Estimating the Cost of Road Crashes in Developing 
Countries. Technical Report.

http://www.transport-links.org/transport_links/filearea/documentstore/105_R\%207780.PDF

[5] BTE (2000) Road Crash Costs in Australia Report 102. https://bitre.gov.au/publications/2000/report_102.aspx

[6] Connelly, L.B. and Supangan, R. (2006) The Economic Costs of Road Traffic Crashes: Australia, States, and Territories. Accident Analysis \& Prevention, 38, 1087-1093. http://dx.doi.org/10.1016/j.aap.2006.04.015

[7] Thongchim, P., Taneerananon, P., Luathep, P. and Prapongsena, P. (2007) Traffic Accident Costing for Thailand. Journal of the Eastern Asia Society for Transportation Studies, 7, 2891-2906.

[8] Antić, B., Vujanić, M., Lipovac, K. and Pešić, D. (2011) Estimation of the Traffic Accidents Costs in Serbia by Using Dominant Costs Model. Transport, 26, 433-440. http://dx.doi.org/10.3846/16484142.2011.635425

[9] Elvik, R. (2000) How Much Do Road Accidents Cost the National Economy? Accident Analysis \& Prevention, 32, 849-851. http://dx.doi.org/10.1016/S0001-4575(00)00015-4

[10] Al-Masaeid, H.R., Al-Mashakbeh, A.A. and Qudah, A.M. (1999) Economic Costs of Traffic Accidents in Jordan. Accident Analysis \& Prevention, 31, 347-357. http://dx.doi.org/10.1016/S0001-4575(98)00068-2

[11] Anh, T.T., Dao, N.X. and Anh, T.T. (2005) The Cost of Road Traffic Accidents in Vietnam. Proceedings of the Eastern Asia Society for Transportation Studies, 5, 1923-1933.

[12] Luathep, P. and Tanaboriboon, Y. (2005) Determination of Economic Losses due to Road Crashes in Thailand. Journal of the Eastern Asia Society for Transportation Studies, 6, 3413-3425.

[13] IMF (2013) Sudan Interim Poverty Reduction Strategy Paper. International Monetary Fund, Washington DC.

[14] Mohan, D. (2002) Social Cost of Road Traffic Crashes in India. Proceedings First Safe Community Conference on Cost of Injury, Viborg, October 2002.

[15] Jacobs, G., Aeron-Thomas, A. and Astrop, A. (2000) Estimating Global Road Fatalities. TRL Report 445.

[16] AICD (2011) Sudan's Infrastructure: A Continental Perspective. Africa Infrastrucure Country Diagnostic: Country Report.

[17] Shariff, A. (2004) A Status Report on Macroeconomics and Health Sector in Sudan. Khartoum.

[18] Elvik, R. (1995) An Analysis of Official Economic Valuations of Traffic Accident Fatalities in 20 Motorized Countries. Accident Analysis and Prevention, 27, 237-247. http://dx.doi.org/10.1016/0001-4575(94)00060-Y

[19] Trawén, A., Maraste, P. and Persson, U. (2002) International Comparison of Costs of a Fatal Casualty of Road Accidents in 1990 and 1999. Accident Analysis and Prevention, 34, 323-332. http://dx.doi.org/10.1016/S0001-4575(01)00029-X

[20] De Beer, E. and van Niekerk, E. (2004) The Estimation of Unit Costs of Road Traffic Accidents in South Africa. National Department of Transport (South Africa), Pretoria.

[21] Chin, H.C., Haque, M.M. and Jean, Y.H. (2006) An Estimate of Road Accident Costs in Singapore. Proceedings of International Conference on Road Safety in Developing Countries, Dhaka, 22-24 August 2006, 28-35.

[22] Murad, M. (2011) Costing Road Traffic Accidents in Ethiopia. A Thesis Report, Addis Ababa Institute of Technology, Addis Ababa.

[23] McMahon, K. and Dahdah, S. (2008) The True Cost of Road Crashes: Valuing Life and the Cost of a Serious Injury. International Road Assessment Programme.

[24] Blincoe, L., Seay, A., Zaloshnja, E., Miller, T., Romano, E., Luchter, S. and Spicer, R.S. (2002) The Economic Impact of Motor Vehicle Crashes, 2000. Report No. DOT HS 809 446, US Department of Transportation, National Highway Traffic Safety Administration, Washington DC.

[25] ETSC (2007) Social and Economic Consequences of Road Traffic Injury in Europe. The European Transport Safety Council, Brussels.

[26] Masniak, D. (n.d.) Social and Economic Costs of Road Accidents in Europe. www.law.muni.cz/sborniky/dp08/files/pdf/financ/masniak.pdf 